\title{
Addition of 1-Hydroxyalkyl Free Radicals to Unsolvated Formaldehyde in Alcohol- Formaldehyde Solutions with Nonbranched-Chain Formation of 1,2-Alkanediols
}

\author{
Michael M. Silaev ${ }^{1 *}$ \\ *lDepartment of Chemistry, Lomonosov Moscow State University, Vorobievy Gory, Moscow 119991, Russia
}

*Corresponding Author: -

Email: mmsilaev@rc.chem.msu.ru

\begin{abstract}
: -
A mechanism of the initiated nonbranched-chain process of forming 1,2-alkanediols and carbonyl compounds in alcoholformaldehyde systems is suggested. The quasi-steady-state treatment is used to obtain kinetic equations that can describe the nonmonotonic (with a maximum) dependences of the formation rates of the products on the concentration of free unsolvated formaldehyde. The experimental concentration of the free unsolvated form of formaldehyde are given at the different temperatures, solvent permittivity, and total concentrations of formaldehyde in water and alcohols. An empirical equation for calculating the free formaldehyde concentration in alcohol-formaldehyde (including water/ethanediolformaldehyde) systems at various temperatures and total formaldehyde concentrations and an equation for evaluating solvent concentrations in these systems were derived.
\end{abstract}

Keywords: nonbranched-chain process, free formaldehyde, 1-hydroxyalkyl radical, formyl radical, competing reaction, equation. 
Free radicals add to the carbon atom at the double bond of the carbonyl group of dissolved free (unsolvated, monomer) formaldehyde. The concentration of free formaldehyde in the solution at room temperature is a fraction of a percent of the total formaldehyde concentration, which includes formaldehyde chemically bound to the solvent [1]. The concentration of free formaldehyde exponentially increases with increasing temperature [2]. The energy released as a result of this addition, when the $\mathrm{C}=\mathrm{O}$ bond is converted into an ordinary bond, is 30 to $60 \mathrm{~kJ} \mathrm{~mol}^{-1}$ (according to the data on the addition of $\mathrm{C}_{1}-\mathrm{C}_{4}$ alkyl radicals in the gas phase under standard conditions [3-6]). The resulting free 1:1 adduct radicals can both abstract hydrogen atoms from the nearest-neighbor molecules of the solvent or unsolvated formaldehyde and, due to its structure, decompose by a monomolecular mechanism including isomerization [7,8].

The analysis of stable liquid-phase products was carried out by the gas chromatographic method. The quasi-steady-state treatment is used to obtain kinetic equations.

\section{Addition of 1-Hydroxyalklyl Free Radicals with Two or More Carbon Atoms}

Free 1-hydroxyalkyl radicals (which result from the abstraction of a hydrogen atom from the carbon atom bonded to the hydroxyl group in molecules of saturated aliphatic alcohols but methanol under the action of chemical initiators [9, 10], light $[11,12]$, or ionizing radiation $[13,14])$ add at the double bond of free formaldehyde dissolved in the alcohol, forming 1,2-alkanediols [7-10, 12-18], carbonyl compounds, and methanol [14, 15] via the chaining mechanism. (The yields of the latter two products in the temperature range of 303 to $448 \mathrm{~K}$ are one order of magnitude lower). In these processes, the determining role in the reactivity of the alcohols can be played by the desolvation of formaldehyde in alcohol-formaldehyde solutions, which depends both on the temperature and on the polarity of the solvent [2, 14]. For the $\gamma$-radiolysis of 1(or 2)-propanol-formaldehyde system at a constant temperature, the dependences of the radiationchemical yields of 1,2-alkanediols and carbonyl compounds as a function of the formaldehyde concentration show maxima and are symbatic $[13,15]$. For a constant total formaldehyde concentration of $1 \mathrm{~mol} \mathrm{dm}^{-3}$, the dependence of the 1,2-alkanediol yields as a function of temperature for 303-473 K shows a maximum, whereas the yields of carbonyl compounds and methanol increase monotonically [14] (along with the concentration of free formaldehyde [2]). In addition to the above products, the nonchain mechanism in the $\gamma$-radiolysis of the solutions of formaldehyde in ethanol and 1 - and 2-propanol gives ethanediol, carbon monoxide, and hydrogen in low radiation-chemical yields (which, however, exceed the yields of the same products in the $\gamma$-radiolysis of individual alcohols) $[7,14,15]$. The available experimental data can be described in terms of the following scheme of reactions.

\section{Scheme}

Chain initiation

1. I $\stackrel{2 k_{1}}{\longrightarrow} 2 \mathrm{R}_{0}^{:}$;

1a. $\mathrm{R}_{0}^{\cdot}+\mathrm{ROH} \stackrel{k_{3}}{\longrightarrow} \mathrm{ROH}+{ }^{\cdot} \mathrm{R}_{(-\mathrm{H})} \mathrm{OH}$.

Chain propagation

2. ${ }^{\mathrm{R}}(-\mathrm{H}) \mathrm{OH}+\mathrm{CH}_{2} \mathrm{O} \stackrel{k_{2}}{\longrightarrow} \mathrm{R}_{(-\mathrm{H})}(\mathrm{OH}) \mathrm{CH}_{2} \mathrm{O}$;

3. $\mathrm{R}_{(-\mathrm{H})}(\mathrm{OH}) \mathrm{CH}_{2} \mathrm{O}^{*}+\mathrm{ROH} \stackrel{k_{3}}{\longrightarrow} \mathrm{R}_{(-\mathrm{H})}(\mathrm{OH}) \mathrm{CH}_{2} \mathrm{OH}+$

$$
\cdot \mathrm{R}_{(-\mathrm{H})} \mathrm{OH} \text {; }
$$

3a. $\mathrm{R}_{(-\mathrm{H})}(\mathrm{OH}) \mathrm{CH}_{2} \mathrm{O}^{\circ} \stackrel{k_{3 a}}{\longrightarrow} \mathrm{R}_{(-2 \mathrm{H})} \mathrm{HO}+{ }^{\circ} \mathrm{CH}_{2} \mathrm{OH}$

(or $\mathrm{R}^{\prime} \mathrm{R}^{\prime \prime} \mathrm{CO}+{ }^{\circ} \mathrm{CH}_{2} \mathrm{OH}$ );

3b. ${ }^{\circ} \mathrm{CH}_{2} \mathrm{OH}+\mathrm{ROH} \stackrel{k_{3 b}}{\longrightarrow} \mathrm{CH}_{3} \mathrm{OH}+{ }^{\cdot} \mathrm{R}_{(-\mathrm{H})} \mathrm{OH}$.

Inhibition

4. $\mathrm{R}_{(-\mathrm{H})}(\mathrm{OH}) \mathrm{CH}_{2} \mathrm{O}^{*}+\mathrm{CH}_{2} \mathrm{O} \stackrel{k_{4}}{\longrightarrow} \mathrm{R}_{(-\mathrm{H})}(\mathrm{OH}) \mathrm{CH}_{2} \mathrm{OH}+$

'CHO.

Chain termination 


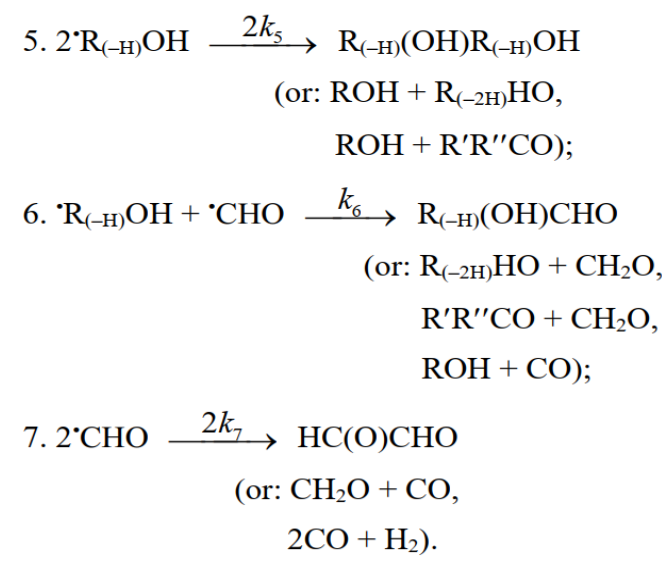

In these reactions, $\mathrm{I}$ is an initiator, e.g., a peroxide $[9,10]$;

$\mathrm{R}_{0}{ }_{0}$, some reactive radical (initiator radical); $\mathrm{R}$, an alkyl; $\mathrm{ROH}$, a saturated aliphatic alcohol, either primary or secondary, beginning from ethanol; $\mathrm{CH}_{2} \mathrm{O}$, the unsaturated molecule - free formaldehyde; ${ }^{\circ} \mathrm{CH}_{2} \mathrm{OH}$, the 1-hydroxymetyl fragment radical; ${ }^{\circ} \mathrm{R}_{(-\mathrm{H})} \mathrm{OH}$, the reactive 1-hydroxyalkyl addend radical, beginning from 1-hydroxyethyl; $\mathrm{R}_{(-\mathrm{H})}(\mathrm{OH}) \mathrm{CH}_{2} \mathrm{O}$ ', the reactive hydroxyalkoxyl 1:1 adduct radical; ${ }^{\circ} \mathrm{CHO}$, the low-reactive formyl radical (inhibitor radical); $\mathrm{R}_{0} \mathrm{H}$, the molecular product; $\mathrm{R}_{(-\mathrm{H})}(\mathrm{OH}) \mathrm{CH}_{2} \mathrm{OH}, 1,2$-alkanediol; $\mathrm{R}_{(-2 \mathrm{H})} \mathrm{HO}$, an aldehyde in the case of a primary alcohol and an R'R"CO ketone in the case of a secondary alcohol; $\mathrm{R}_{(-\mathrm{H})}(\mathrm{OH}) \mathrm{R}_{(-\mathrm{H})} \mathrm{OH}$, a vicinal alkanediol; $\mathrm{R}_{(-\mathrm{H})}(\mathrm{OH}) \mathrm{CHO}$, a hydroxyaldehyde. The chain evolution stage of Scheme includes consecutive reaction pairs 2-3, 2-3a, and 3a-3b; parallel (competing) reaction pairs $3-3 a, 3-3 b, 3-4$, and 3a-4; and consecutive-parallel reactions 2 and 4.

In addition, it seems unlikely that free adduct radicals will add to formaldehyde at higher temperatures the reaction of adding is unlikely because this would result in an ether bond. The addition of hydroxymethyl radicals to formaldehyde, which is in competition with reaction $3 \mathrm{~b}$, is not included as well, because there is no chain formation of ethanediol at 303-448 K [14]. At the same time, small amounts of ethanediol can form via the dimerization of a small fraction of hydroxymethyl radicals, but this cannot have any appreciable effect on the overall process kinetics. The addition of free formyl radicals to formaldehyde cannot proceed at a significant rate, as is indicated by the fact that there is no chain formation of glycol aldehyde in the systems examined [14].

The mechanism of the decomposition of the free adduct radical via reaction $3 \mathrm{a}$, which includes the formation of an intramolecular $\mathrm{H} \cdots$ bond and isomerization, can be represented as follows $[7,8,15]$ :

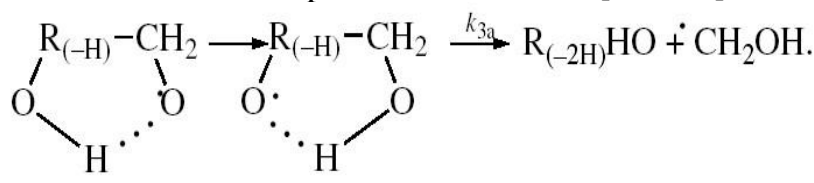

The probability of the occurrence of reaction 3a should increase with increasing temperature. This is indicated by experimental data presented above $[7,8,15]$. The decomposition of the hydroxyalkoxyl radical. $\mathrm{R}_{(-\mathrm{H})}(\mathrm{OH}) \mathrm{CH}_{2} \mathrm{O}^{\bullet}(\mathrm{reaction}$ $3 \mathrm{a}$ ) is likely endothermic. The endothermic nature of reaction $3 \mathrm{a}$ is indirectly indicated by the fact that the decomposition of simple $\mathrm{C}_{2}-\mathrm{C}_{4}$ alkoxyl radicals $\mathrm{RO}^{*}$ in the gas phase is accompanied by heat absorption: $\left(\Delta H_{298}{ }^{\mathrm{O}}=30-90 \mathrm{~kJ} \mathrm{~mol}^{-1}[4-\right.$ 6]). Reaction 3b, subsequent to reaction 3a, is exothermic, and its heat for $\mathrm{C}_{2}-\mathrm{C}_{3}$ alcohols in the gas phase is $\Delta H_{298} \mathrm{O}=-40$ to $-60 \mathrm{~kJ} \mathrm{~mol}^{-1}[4-6]$. As follows from the above scheme of the process, reactions $3 \mathrm{a}$ and $3 \mathrm{~b}$, in which the formation and consumption of the highly reactive free radical hydroxymethyl take place (at equal rates under steady-state conditions), can be represented as a single bimolecular reaction 3a,b occurring in a "cage" of solvent molecules.

The free formyl radical resulting from reaction 4 , which is in competition with reactions 3 and $3 a$, is comparatively lowreactive because its spin density can be partially delocalized from the carbon atom via the double bond toward the oxygen atom, which possesses a higher electron affinity [3]. For example, in contrast to the methyl and alkoxyl $\pi$-radicals, the formyl $\sigma$-radical can be stabilized in glassy alcohols at $77 \mathrm{~K}$ [19]. In the gas phase, the dissociation energy of the $\mathrm{C}-\mathrm{H}$ bond in formyl radicals is half that for acetyl radicals and is about 5 times lower than the dissociation energy of the $\mathrm{C}_{\alpha-}$ $\mathrm{H}$ bond in saturated $\mathrm{C}_{1}-\mathrm{C}_{3}$ alcohols [3].

As distinct from reactions 3 and $3 \mathrm{a}, \mathrm{b}$, reaction 4 leads to an inefficient consumption of hydroxyalkoxyl adduct radicals, without regenerating the initial 1-hydroxyalkyl addend radicals. Reaction 4 together with reaction 6 (mutual annihilation of free formyl and chain-carrier 1-hydroxyalkyl radicals) causes the inhibition of the nonbranched-chain process. For the disproportionation of the free radicals, the heats of reactions 5-7 for $\mathrm{C}_{1}-\mathrm{C}_{3}$ alcohols in the gas phase vary in the range of $\Delta H_{298}{ }^{\mathrm{o}}=-135$ to $-385 \mathrm{~kJ} \mathrm{~mol}^{-1}$ [3-6]. The rates of the chain formation of 1,2-alkanediols in reaction 3 (and their nonchain formation in reaction 4), carbonyl compounds in reaction $3 \mathrm{a}$, and methanol in reaction $3 \mathrm{~b}$ are given by the following equations ${ }^{1}$ : 


$$
\begin{gathered}
V_{3,4}\left(\mathrm{R}_{(-\mathrm{H})}(\mathrm{OH}) \mathrm{CH}_{2} \mathrm{OH}\right)= \\
\frac{V_{1}(\alpha l+x) k_{2} x}{k_{2} x^{2}+(\alpha l+\beta+x) \sqrt{2 k_{5} V_{1}}}, \\
V_{3 \mathrm{a}}\left(\mathrm{R}_{(-2 \mathrm{H})} \mathrm{HO}\right)=V_{3 \mathrm{~b}}\left(\mathrm{CH}_{3} \mathrm{OH}\right)= \\
\frac{V_{1} \beta k_{2} x}{k_{2} x^{2}+(\alpha l+\beta+x) \sqrt{2 k_{5} V_{1}}},
\end{gathered}
$$

where $V_{1}$ is the initiation rate, $l$ is the molar concentration of the saturated alcohol at the given total concentration $c_{0}$ of formaldehyde dissolved in it, $x$ is the molar concentration of free formaldehyde $(l>>x), k_{2}$ is the rate constant of reaction 2 (addition of 1-hydroxyalkyl free radical to free formaldehyde), and $\alpha=k_{3} / k_{4}$ and $\beta=k_{3 \mathrm{a}} / k_{4}\left(\mathrm{~mol} \mathrm{dm}^{-3}\right)$ are the ratios of the rate constants of the competing (parallel) reactions. Estimates of $2 k_{5}$ were reported by Silaev et al. [22, 24]. From the extremum condition for the reaction 3 a rate function, $\partial V_{3 a} / \partial x=0$, we derived the following analytical expression: $k_{2}=\left(\alpha l_{m}+\beta\right) \sqrt{2 k_{5} V_{1}} / x_{m}^{2}$.

Equations (1) and (2) taken on the condition that $k_{2} \mathrm{x}^{2}>(\alpha l+x) \sqrt{2 k_{5} V_{1}}$ (the descending branch of the curve having a maximum) can be transformed to equations that can be used for a preliminary estimation of parameters $\alpha$ and $\beta$ :

$$
\begin{aligned}
V_{3,4} & =\left(V_{1} / \varphi\right)[(\alpha l / x)+1], \\
V_{3 \mathrm{a}} & =V_{3 \mathrm{~b}}=V_{1} \beta / \varphi x,
\end{aligned}
$$

where $\varphi=2$ for the maximum (when $k_{2} x^{2} \cong(\alpha l+x) \sqrt{2 k_{5} V_{1}}$ ) and $\varphi=1$ for the descending portion of the curve.

The overall process rate is a complicated function of the formation and disappearance rates of the ${ }^{\circ} \mathrm{R}_{(-\mathrm{H})} \mathrm{OH}$ and ${ }^{\circ} \mathrm{CHO}$ free radicals:

$$
\begin{gathered}
V\left(\mathrm{R}_{(-\mathrm{H})}(\mathrm{OH}) \mathrm{CH}_{2} \mathrm{OH}, \mathrm{R}_{(-2 \mathrm{H})} \mathrm{HO}, \mathrm{CH}_{3} \mathrm{OH}\right)= \\
V_{1 \mathrm{a}}+V_{3}+V_{3 \mathrm{~b}}-V_{4}-V_{5}+V_{7}
\end{gathered}
$$

The ratios of the rates of the competing reactions are $V_{3} / V_{4}=\alpha l / x$ and $V_{3 \mathrm{a}} / V_{4}=\beta / x$, and the chain length is $v=\left(V_{3}+\right.$ $\left.V_{3 \mathrm{a}}\right) / V_{1}$. The ratio of the rates of formation of 1,2-alkanediol and the carbonyl compound is a simple linear function of $x$ :

$$
\begin{gathered}
V_{3,4}\left(\mathrm{R}_{(-\mathrm{H})}(\mathrm{OH}) \mathrm{CH}_{2} \mathrm{OH}\right) / V_{3 \mathrm{a}}\left(\mathrm{R}_{(-2 \mathrm{H})} \mathrm{HO}\right)= \\
\left(k_{4} / k_{3 \mathrm{a}}\right) x+\left(k_{3} / k_{3 \mathrm{a}}\right) l .
\end{gathered}
$$

The equations for the rates of chain-termination reactions 5-7 are given by the following equations:

$$
\begin{gathered}
V_{5}=V_{1}^{2} 2 k_{5}(\alpha l+\beta+x)^{2} / f^{2}, \\
2 V_{6}=2 V_{1} \sqrt{2 k_{5} V_{1}}(\alpha l+\beta+x) k_{2} x^{2} / f^{2}, \\
V_{7}=V_{1}\left(k_{2} x^{2}\right)^{2} / f^{2},
\end{gathered}
$$

where $f=k_{2} x^{2}+(\alpha l+\beta+x) \sqrt{2 k_{5} V_{1}}$.

Neutral formaldehyde solutions in alcohols at room temperature primarily consist of a mixture of formaldehyde polymer solvates reversibly bound to alcohols; these polymer solvates differ in molecular mass and have the general formula $\mathrm{RO}\left(\mathrm{CH}_{2} \mathrm{O}\right)_{n} \mathrm{H}$, where $\mathrm{n}=1-4$ [1]. The concentration of formaldehyde that occurs in solution as a free, unsolvated active species chemically unbound to the solvent (this species is capable of scavenging free radicals) at room temperature is lower than a percent of the total formaldehyde concentration [1]. The concentration $x$ of the free formaldehyde species in solutions was determined by high-temperature UV spectrophotometry in the range $335-438 \mathrm{~K}$ at the total formaldehyde concentration $c_{0}$ (free and bound species including the concentration of polymer solvates) of $1.0-8.4 \mathrm{~mol} \mathrm{dm}^{-3}$ in water, ethanediol, methanol, ethanol, 1-propanol, 2-propanol, and 2-methyl-2-propanol [2] (see Table of the Appendix). This concentration increases with temperature according to an exponential law, and it can be as high as a few percent of the total concentration in solution under the test conditions, up to $19.3 \%$ in the case of 2-methyl-2-propanol at a total concentration of $1.0 \mathrm{~mol} \mathrm{dm}^{-3}$ and a temperature of $398 \mathrm{~K}$. The following empirical equation relating the concentration $x$ $\left(\mathrm{mol} \mathrm{dm}{ }^{-3}\right)$ of free formaldehyde to temperature $T(\mathrm{~K})$ and the total concentration $c_{0}$ in the solution (measured at room temperature), was developed by the treatment of 101 data points [2, 22]:

$$
\lg x=-a\left(10^{3} / T\right)+b+h \lg c_{0}
$$

where the coefficients $a$ and $b$ were calculated as the parameters of a straight-line equation by the least-squares technique from the dependence of $\lg x$ on $1 / T$ at $c_{0}=1.0 \mathrm{~mol} \mathrm{dm}^{-3}$ for various solvents, and the coefficient $h$ was obtained as the average value of the slopes of $\lg x$ as linear functions of $\lg c_{0}$ at various series of fixed temperatures. The Table 1 
summarizes these coefficients for each solvent. As regards the experimental data, the error in the calculations of the concentration $x$ of free formaldehyde made by Eq. (8) in the specified temperature range was no higher than $25 \%$.

Table 1. Coefficients of the empirical Eq. (8) for the estimation of the concentration $x$ of free formaldehyde in polar solvent-formaldehyde systems

\begin{tabular}{|l|l|l|l|}
\hline \multirow{2}{*}{ Solvent } & \multicolumn{3}{|c|}{ Coefficient } \\
\cline { 2 - 4 } & $\boldsymbol{a}$ & $\boldsymbol{b}$ & $\boldsymbol{h}$ \\
\hline Water & 2.36 & 4.45 & 0.80 \\
\hline Ethanediol & 1.83 & 2.60 & 1.28 \\
\hline Methanol & 3.11 & 5.58 & $0.22 c_{0} / \lg c_{0}$ \\
\hline Ethanol & 3.10 & 5.92 & $1.10\left(10^{3} / T\right)-1.44$ \\
\hline 1-Propanol & 2.42 & 4.47 & 1.30 \\
\hline 2-Propanol & 2.42 & 4.64 & 1.05 \\
\hline 2-Methyl-2-propanol & 3.19 & 7.31 & 0.96 \\
\hline
\end{tabular}

On the assumption that the dependence of the density of a given solution on the concentration of formaldehyde is similar to the analogous linear dependence found for aqueous formaldehyde solutions $\left(0-14 \mathrm{~mol} \mathrm{dm}^{-3} ; 291 \mathrm{~K}\right)$ [25], the concentrations $l_{\mathrm{T}}\left(\mathrm{mol} \mathrm{dm}^{-3}\right)$ of alcohols in alco hol-formaldehyde solutions at a certain temperature can be estimated by the equation

$$
l_{\mathrm{T}}=\frac{\left(10^{3} d-21.6 c_{0}\right) d_{\mathrm{T}}}{\left(d+8.4 \times 10^{-3} c_{0}\right) M},
$$

Where $c 0$ is the total formaldehyde concentration $\left(\mathrm{mol} \mathrm{dm}{ }^{-3}\right) ; M$ is the molecular mass $\left(\mathrm{g} \mathrm{mol}^{-1}\right)$ of the solvent; $d$ and $d_{\mathrm{T}}$ are the solvent densities $\left(\mathrm{g} \mathrm{cm}^{-3}\right)$ at room and given temperatures, respectively; the coefficients $8.4 \times 10^{-3}$ and 21.6 have the units of $10^{3} \mathrm{~g} \mathrm{~mol}^{-1}$ and $\mathrm{g} \mathrm{mol}^{-1}$, respectively

Earlier [2], it was found that the concentration $x$ of the free formaldehyde species decreased with the solvent permittiv ity $D_{298}$ at a constant temperature. Water is an exception.

Although water is more polar than alcohols, the concentration $x$ of free formaldehyde in an aqueous solution is anomalously high and reaches the level of its concentration in 2-propanol, all other factors being the same (see Fig. 1) [2, 22]. This can be due to the specific instability of hydrated formaldehyde species and the ease of their conversion into free formaldehyde with increasing temperature.

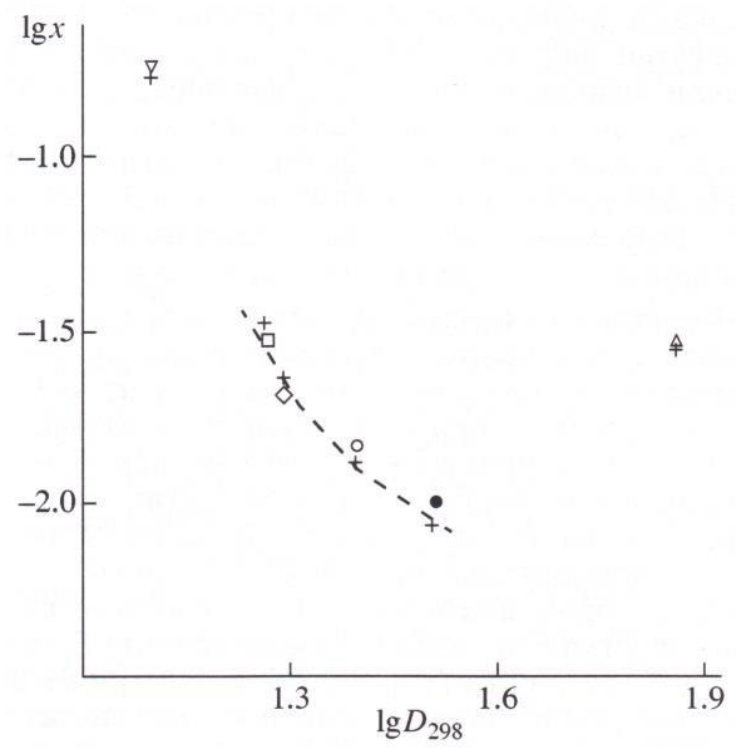

Fig. 1. Logarithmic plot of the experimental concentrations $x\left(\mathrm{~mol} \mathrm{dm}^{-3}\right)$ of free formaldehyde at its total concentration $c_{0}=1.0 \mathrm{~mol} \mathrm{dm}{ }^{-3}$ and $395 \pm 3 \mathrm{~K}$ in $(\Delta)$ water, $(\bullet)$ methanol, (o) ethanol, $(\diamond)$ 1-propanol, $(\square)$ 2-propanol, and $(\nabla)$ 2-methyl2-propanol as functions of the permittivity $D_{298}$ of these solvents (+ refers to the concentrations $x$ in the above solvents calculated by empirical Eq. (8)).

As an example, the Fig. 2 illustrates the use of Eqs. (1) and (2) for describing the experimental dependences of the formation rates of 1,2-butanediol (curve 1) in reactions 3 and 4 and propanal (curve 2) in reaction 3 a on the concentration $x$ of free formaldehyde in the 1-propanol-formaldehyde re- acting system at the total formaldehyde concentration $c_{0}$ of 2.0 to $9.5 \mathrm{~mol} \mathrm{dm}^{-3}$ and temperature of $413 \mathrm{~K}[7,15,26]$. The concentration dependence of the propanal formation rate was described using the estimates of kinetic parameters obtained for the same dependence of the 1,2-butanediol formation rate. We considered these data more reliable for the reason that the carbonyl compounds forming in the alco- hol- 
formaldehyde systems can react with the alcohol and this reaction depends considerably on the temperature and acidity of the medium [1]. The mathematical modeling of the process was carried out using a ${ }^{137} \mathrm{Cs} \gamma$-radiation dose rate of $P=$ $0.8 \mathrm{~Gy} \mathrm{~s}^{-1}[13,26]$, a total initiation yield of $G\left(\mathrm{CH}_{3} \mathrm{CH}_{2} \dot{\mathrm{CHOH}}\right)=9.0$ particles per $100 \mathrm{eV}[7,15]\left(V_{1}=4.07 \times 10^{-7} \mathrm{~mol}\right.$ $\mathrm{dm}^{-3} \mathrm{~s}^{-1}$ ), and $2 k_{5}=4.7 \times 10^{9} \mathrm{dm}^{3} \mathrm{~mol}^{-1} \mathrm{~s}^{-1}$. The following values of the parameters were obtained: $\alpha=0.36 \pm 0.07, \beta=$ $0.25 \pm 0.05 \mathrm{~mol} \mathrm{dm}^{-3}$, and $k_{2}=(6.0 \pm 1.4) \times 10_{3} \mathrm{dm}_{3} \mathrm{~mol}_{-1} \mathrm{~s}-1$.

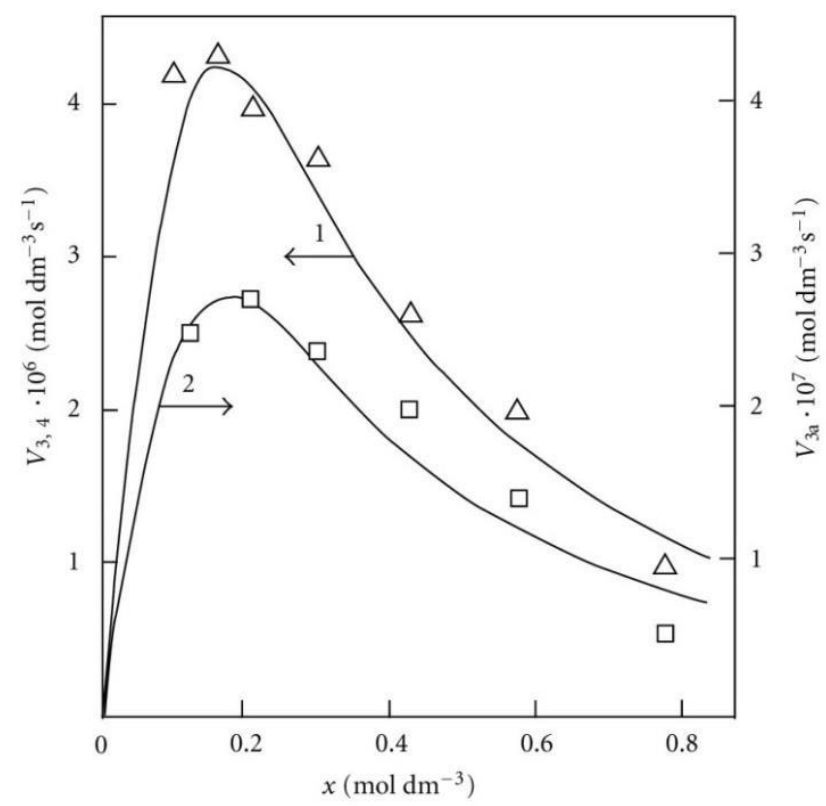

Fig. 2. Reconstruction of the functional dependence (curves) of the product formation rates $V_{3,4}$ and $V_{3 a}$ on the concentration $x$ of free formaldehyde (model optimization with respect to the parameters $\alpha, \beta$ and $k_{2}$ ) from empirical data (symbols) for the 1-propanol-formaldehyde system at $413 \mathrm{~K}[7,15,26]:(1, \Delta)$ calculation using Eq. (1), the product is 1,2-butanediol, standard deviation of $S_{Y}=2.20 \times 10^{-7} ;(2, \square)$ calculation using Eq. (2), the product is propanal, $S_{\mathrm{Y}}=2.38$ $\times 10^{-8}$

Note that, as compared to the yields of 1,2-propanediol in the $\gamma$-radiolysis of the ethanol-formaldehyde system, the yields of 2,3-butanediol in the $\gamma$-radiolysis of the ethanol-acetaldehyde system are one order of magnitude lower [26]. Using data from [7, 15], it can be demonstrated that, at $433 \mathrm{~K}$, the double bond of 2-propen-1-ol accepts the 1-hydroxyethyl radical 3.4 times more efficiently than the double bond of formaldehyde [27].

\section{Addition of Hydroxymethyl Free Radicals}

The addition of hydroxymethyl radicals to the carbon atom at the double bond of free formaldehyde molecules in methanol, initiated by the free-radical mechanism, results in the chain formation of ethanediol [16]. In this case, reaction 3a in Scheme is the reverse of reaction 2, the 1-hydroxyalkyl radical ${ }^{\circ} \mathrm{R}_{(-\mathrm{H})} \mathrm{OH}$ is the hydroxymethyl $\operatorname{radical}^{\circ} \mathrm{CH}_{2} \mathrm{OH}$, so reaction $3 \mathrm{~b}$ is eliminated $\left(k_{3 \mathrm{~b}}=0\right)$, and reaction 5 yields an additional amount of ethanediol via the dimerization of chaincarrier hydroxymethyl radicals (their disproportionation can practically be ignored [28]). The scheme of these reactions is presented in [17].

The rate equation for ethanediol formation by the chain mechanism in reaction 3 and by the nonchain mechanism in reactions 4 and 5 in the methanol-formaldehyde system has a complicated form as compared to Eq. (1) for the formation rate of the other 1,2-alkanediols [8]:

$$
\begin{gathered}
V_{3,4,5}\left(\mathrm{CH}_{2} \mathrm{OH}\right)_{2}= \\
V_{1}\left[f(\alpha l+x) k_{2} x+V_{1} 2 k_{5}(\alpha l+\beta+x)^{2}\right] / f^{2},
\end{gathered}
$$

where $f=k_{2} x^{2}+(\alpha l+\beta+x) \sqrt{2 k_{5} V_{1}}$.

Equation (10) when $k_{2} x^{2} \ll(\alpha l+\beta+x) \sqrt{2 k_{5} V_{1}}$ (ascending branch of the curve having a maximum) and $\alpha l>>\beta$ (practically without reaction 3a) is transformed to a simple directly-proportional dependence on the concentration $x$ of free formaldehyde, which can be used to pre-estimate the parameter $k_{2}$ :

$$
V_{3,4,5}=\left(V_{1} / \varphi^{2}\right)\left[\left(\varphi k_{2} x / \sqrt{2 k_{5} V_{1}}\right)+1\right]
$$

where $\varphi=1$ for the ascending portion of the curve and $\varphi=2$ for the maximum, when $k_{2} x^{2} \cong(\alpha l+\beta+x) \sqrt{2 k_{5} V_{1}}$. If the rate of ethanediol formation by the dimerization mechanism in reaction 5 is ignored for the reason that it is small as compared to the total rate of ethanediol formation in reactions 3 and 4, Eq. (10) will be identical to Eq. (1). After the numerator and denominator on the right-hand side of Eq. (1) are divided by $k_{-2} \equiv k_{3 \mathrm{a}}$, one can replace $k_{2}$ in this equation with $K_{2}=k_{2} / k_{-}$ 2, which is the equilibrium constant for the reverse of reaction 2 . Ignoring the reverse step of reaction $2\left(k_{3 \mathrm{a}}=0, \beta=0\right)$ can further simplify Eq. (1). In this case, the rate constant $k_{2}$ is effective. 


\section{References}

[1].S. K. Ogorodnikov, Formal'degid (Formaldehyde), Khimiya, Leningrad, 1984.

[2].M. M. Silaev, A. V. Rudnev, and E. P. Kalyazin, "Formaldehyde. III. Concentration of Free Formaldehyde as a Function of Temperature, Polarity of Solvents, and Total Concentration of Formaldehyde in Solution”, Zhurnal Fizicheskoi Khimii, 1979 , vol. 53, no. 7, pp. 1647-1651.

[3].L. V. Gurvich, G. V. Karachevtsev, V. N. Kondrat'ev, Yu. A. Lebedev, V. A. Medvedev, V. K. Potapov, and Yu. S. Khodeev, "Energii razryva khimicheskikh svyazei. Potentsialy ionizatsii i srodstvo k elektronu"("Bond Dissociation Energies, Ionization Potentials, and Electron Affinity"), V. N. Kondrat'ev, Editor, Nauka, Moscow, 1974.

[4].S. W. Benson, "Thermochemical Kinetics: Methods for the Estimation of Thermochemical Data and Rate Parameters", 2nd Edition, Wiley, New York, 1976.

[5].J. B. Pedley, R. D. Naylor, and S. P. Kirby, "Thermochemical Data of Organic Compounds", 2nd Edition, Chapman \& Hall, London, 1986.

[6].Yu. D. Orlov, Yu. A. Lebedev, and I. Sh. Saifullin, "Termokhimiya organicheskikh svobodnykh radikalov" ("Thermochemistry of Organic Free Radicals"), A. M. Kutepov, Editor, Nauka, Moscow, 2001.

[7].M. M. Silaev and L. T. Bugaenko, "Kinetics of the Addition of $\alpha$-Hydroxyalkyl Radicals to 2-Propen-1-ol and Formaldehyde", Kinetics and Katalysis, 1994, vol. 35, no. 4, pp. 509-513, English Translation in: Kinetics and Katalysis, 1994, vol. 35, no. 4, 1994, pp. 463-467.

[8].M. M. Silaev, "Simulation of Nonbranched Chain Processes for Producing 1,2-Alkanediols in Alcohol-Formaldehyde Systems", Teoreticheskie Osnovy Khimicheskoi Tekhnologii, 2007, vol. 41, no. 4, pp. 379-384, English Translation in: Thoretical Foundations Chemical Engineering, 2007, vol. 41, no. 4, pp. 357-361.

[9].Oyama, M., "A Free-Radical Reaction of Primary and Secondary Alcohols with Formaldehyde", The Journal of Organic Chemistry, 1965, vol. 30, no. 7, pp. 2429-2432.

[10]. G. I. Nikishin, D. Lefor, and E. D. Vorob'ev, "Free Radical Reaction of Primary Alcohols with Formaldehyde", Izvestiya Akademii Nauk SSSR, Ser. Khimiya, 1966, no. 7, pp. 1271-1272.

[11]. W. H. Urry, F. W. Stacey, E. S. Huyser, and O. O. Juveland, "The Peroxide- and Light-Induced Additions of Alcohols to Olefins", Journal of the American Chemical Society, 1954, vol. 76, no. 2, pp. 450-455.

[12]. M. B. Dzhurinskaya, A. V. Rudnev, and E. P. Kalyazin, "High Temperature UV Photolysis of Formaldehyde in Liquid Methanol”, Vestnik Moskovskogo Universiteta, Ser. 2: Khimiya, 1984, vol. 25, no. 2, pp. 173-176.

[13]. E. P. Kalyazin, E. P. Petryaev, and O. I Shadyro, "Reaction between Oxyalkyl Radicals and Aldehydes", Zhurnal Organicheskoi Khimii, 1977, vol. 13, no. 2, pp. 293-295.

[14]. A. I. Novoselov, A.I., Silaev, M.M., and L. T. Bugaenko, "Effect of Temperature on the Yields of Final Products in the $\gamma$ Radiolysis of Formaldehyde Solutions in $\mathrm{C}_{1}-\mathrm{C}_{3}$ Alkanols", Khimiya Vysokich Energii, 2004, vol. 38, no. 4, pp. 270-272, English Translation in: High Energy Chemistry, 2004, vol. 38, no. 4, 2004, pp. 236-238.

[15]. M. M. Silaev and L. T. Bugaenko, "Mathematical Simulation of the Kinetics of Radiation Induced Hydroxyalkylation of Aliphatic Saturated Alcohols", Radiation Physics and Chemistry, 1992, vol. 40, no. 1, pp. 1-10.

[16]. A. I. Novoselov, M. M. Silaev, and L. T. Bugaenko, "Dependence of Ethanediol Yield on Formaldehyde Concentration in $\gamma$ Radiolysis of Methanol-Formaldehyde System at 373-473 K", Khimiya Vysokikh Energii, 2008, vol. 42, no. 1, pp. 74-75, English Translation in: High Energy Chemistry, 2008, vol. 42, no. 1, pp. 69-70.

[17]. A. I. Novoselov, M. M. Silaev, and L. T. Bugaenko, " $\gamma$-Induced Single-Step Synthesis of Ethylene Glycol from MethanolFormaldehyde Solution", Theoreticheskie Osnovy Khimicheskoy Tekhnologii, 2010, vol. 44 , no. 4, pp. 450-453, English Translation in: Theoretical Foundation of Chemical Engineering, 2010, vol. 44, no. 4, pp. 432-435.

[18]. A. I. Novoselov, M. M. Silaev, and L. T. Bugaenko, "Dependence of 1,2-Propanediol Yield on Formaldehyde Concentration in $\gamma$-Radiolysis of Ethanol-Formaldehyde System at 373-473 K", Khimiya Vysokikh Energii, 2007, vol. 41, no. 1, p. 58, English Translation in: High Energy Chemistry, 2007, vol. 41, no. 1, p. 53.

[19]. S. Ya. Pshezhetskii, A. G. Kotov, V. K. Milinchuk, V. A. Roginskii, and V. I. Tupikov, "EPR svobodnykh radikalov v radiatsionnoi khimii" ("ESR of Free Radicals in Radiation Chemistry"), Khimiya, Moscow, 1972.

[20]. L. Bateman, “Olefin Oxidation”, Quarterly Reviews, 1954, vol. 8, no. 2, pp. 147-167.

[21]. M. M. Silaev, "Simulation of the Nonbranched-Chain Addition of Saturated Free Radicals to Alkenes and Their Derivatives Yielding 1:1 Adducts", Teoreticheskie Osnovy Khimicheskoi Tekhnologii, 2007, vol. 41, no. 3, pp. 280-295, English Translation in: Theoretical Foundations of Chemical Engineering, 2007, vol. 41, no. 3, pp. 273-278.

[22]. M. M. Silaev, "Applied Aspects of the $\gamma$-Radiolysis of $\mathrm{C}_{1}-\mathrm{C}_{4}$ Alcohols and Binary Mixtures on Their Basis", Khimiya Vysokikh Energii, 2002, vol. 36, no. 2, pp. 97-101, English Translation in: High Energy Chemistry, 2002, vol. 36, no. 2, pp. 70-74.

[23]. M. M. Silaev, "Estimating the Solvent Concentration in Formaldehyde Solutions at Various Temperatures", Zhurnal Fizicheskoy Khimii, 1993, vol. 67, no. 9, p. 1944.

[24]. M. M. Silaev, L. T. Bugaenko, and E. P. Kalyazin, "On the Possibility of Adequately Estimating of the Rate Constants for the Reaction of Hydroxyalkyl Radicals with Each Other Using the Self-Diffusion Coefficients or Viscosities of the Corresponding Alcohols", Vestnik Moskovskogo. Univiversiteta, Ser. 2: Khimiya, 1986, vol. 27, no. 4, pp. 386-389.

[25]. J. F. Walker, Formaldehyde, Reinhold, New York, 1953, English Translation under the title Formal'degid, Goskhimizdat, Moscow, 1957, p. 106.

[26]. O. I. Shadyro, "Radiation-chemical Conversions of Aldehydes in Various Systems", Ph.D. Thesis (Chemistry), Belarusian State University, Minsk, 1975.

[27]. M. M. Silaev, "Relative Reactivity of $\alpha$-Hydroxyethyl Radicals for 2-Propene-1-ol and Formaldehyde Double-Bond Addition", Vestnik Moskovskogo Universiteta, Ser. 2: Khimiya, 1993, vol. 34, no. 3, p. 311.

[28]. H. Seki, R. Nagai, and M. Imamura, " $\gamma$-Radiolysis of a Binary Mixture of Methanol and Water. The Formation of Formaldehyde in the Radiolysis of Liquid Methanol”, Bulletin of the Chemical Society of Japan, 1968, vol. 41, no. 12, pp. $2877-2881$.

\section{Appendix}

Table. The experimental concentrations $x\left(\mathrm{~mol} \mathrm{dm}^{-3}\right)$ of free formaldehyde at different temperatures $T(\mathrm{~K})$ and total for- 
maldehyde concentrations $c_{0}\left(\mathrm{~mol} \mathrm{dm}^{-3}\right)$ in various solvents

\begin{tabular}{|c|c|c|c|c|c|c|c|c|c|c|c|}
\hline$c_{0}$ & $T$ & $10^{2} x$ & $c_{0}$ & $T$ & $10^{2} x$ & $c_{0}$ & $T$ & $10^{2} x$ & $c_{0}$ & $T$ & $10^{2} x$ \\
\hline \multicolumn{3}{|c|}{ Water } & 4.44 & 389 & 5.20 & 4.0 & 381 & 5.00 & 1.8 & 371 & 2.08 \\
\hline 1.0 & 358 & 0.78 & 4.44 & 405 & 7.50 & 4.0 & 397 & 8.80 & 1.8 & 393 & 6.00 \\
\hline 1.0 & 387 & 2.22 & 4.44 & 418 & 10.0 & 4.0 & 409 & 12.00 & 1.8 & 418 & 12.20 \\
\hline 1.0 & 393 & 3.23 & \multicolumn{3}{|c|}{ Methanol } & 6.2 & 347 & 2.80 & 1.8 & 438 & 16.70 \\
\hline 1.0 & 407 & 4.55 & 1.0 & 375 & 0.33 & 6.2 & 376 & 7.80 & 3.0 & 343 & 1.25 \\
\hline 2.0 & 353 & 1.44 & 1.0 & 395 & 1.00 & 6.2 & 393 & 12.50 & 3.0 & 375 & 5.40 \\
\hline 2.0 & 387 & 4.70 & 1.0 & 423 & 2.90 & \multicolumn{3}{|c|}{ 1-Propanol } & 3.0 & 403 & 15.80 \\
\hline 2.0 & 397 & 6.60 & 2.5 & 373 & 0.60 & 1.0 & 371 & 0.83 & 3.0 & 413 & 19.40 \\
\hline 2.0 & 407 & 8.55 & 2.5 & 385 & 1.15 & 1.0 & 393 & 2.10 & 5.6 & 343 & 2.80 \\
\hline 4.0 & 343 & 0.78 & 2.5 & 398 & 1.80 & 1.0 & 413 & 4.30 & 5.6 & 358 & 3.35 \\
\hline 4.0 & 363 & 2.33 & 5.4 & 351 & 0.78 & 1.0 & 435 & 7.65 & 5.6 & 363 & 5.80 \\
\hline 4.0 & 385 & 6.45 & 5.4 & 383 & 3.70 & 1.9 & 353 & 0.70 & 5.6 & 371 & 6.50 \\
\hline 4.0 & 403 & 8.90 & 5.4 & 398 & 6.80 & 1.9 & 383 & 3.06 & 5.6 & 383 & 12.10 \\
\hline 4.0 & 413 & 11.10 & 7.0 & 365 & 4.70 & 1.9 & 405 & 7.65 & \multicolumn{3}{|c|}{ 2-Methyl-2-propanol } \\
\hline 6.0 & 351 & 2.22 & 7.0 & 383 & 12.50 & 1.9 & 417 & 11.70 & 1.0 & 347 & 1.20 \\
\hline 6.0 & 375 & 6.70 & 7.0 & 391 & 16.00 & 4.0 & 349 & 1.67 & 1.0 & 367 & 4.50 \\
\hline 6.0 & 389 & 10.70 & \multicolumn{3}{|c|}{ Ethanol } & 4.0 & 373 & 6.10 & 1.0 & 387 & 11.00 \\
\hline 6.0 & 398 & 14.10 & 1.0 & 367 & 0.33 & 4.0 & 393 & 13.30 & 1.0 & 398 & 19.30 \\
\hline 8.4 & 364 & 5.50 & 1.0 & 387 & 0.67 & 6.0 & 338 & 1.39 & 2.0 & 335 & 1.10 \\
\hline 8.4 & 376 & 8.32 & 1.0 & 397 & 1.45 & 6.0 & 357 & 5.00 & 2.0 & 357 & 4.30 \\
\hline 8.4 & 388 & 10.97 & 1.0 & 413 & 2.70 & 6.0 & 377 & 11.70 & 2.0 & 375 & 13.00 \\
\hline Ethar & diol & & 1.0 & 423 & 4.00 & 6.0 & 389 & 18.30 & 2.0 & 383 & 18.50 \\
\hline 1.0 & 409 & 1.30 & 2.0 & 373 & 1.10 & 7.8 & 343 & 3.06 & 3.0 & 338 & 1.70 \\
\hline 1.0 & 418 & 1.80 & 2.0 & 394 & 2.90 & 7.8 & 358 & 6.25 & 3.0 & 353 & 4.70 \\
\hline 1.0 & 435 & 2.45 & 2.0 & 409 & 5.80 & 7.8 & 377 & 16.90 & 3.0 & 365 & 9.60 \\
\hline 3.33 & 358 & 1.20 & 2.0 & 419 & 8.20 & \multicolumn{3}{|c|}{ 2-Propanol } & 3.0 & 373 & 15.50 \\
\hline 3.33 & 387 & 3.30 & 3.0 & 361 & 1.20 & 1.0 & 365 & 0.98 & 6.0 & 345 & 6.90 \\
\hline 3.33 & 401 & 5.10 & 3.0 & 387 & 3.70 & 1.0 & 393 & 3.05 & 6.0 & 351 & 9.00 \\
\hline 3.33 & 415 & 7.20 & 3.0 & 409 & 7.80 & 1.0 & 411 & 6.00 & 6.0 & 361 & 13.40 \\
\hline 4.44 & 338 & 1.00 & 4.0 & 355 & 2.30 & 1.0 & 433 & 10.40 & 6.0 & 365 & 18.30 \\
\hline
\end{tabular}

